\title{
Autocontingencies: Rats count to three to predict safety from shock
}

\author{
HANK DAVIS and JOHN MEMMOTT \\ University of Guelph, Ontario, Canada
}

\begin{abstract}
Following training on a variable-interval food-reinforcement schedule, rats were exposed to three unsignaled shocks during each 30-min session. Although leverpressing was initially suppressed, responding was significantly accelerated following offset of the third shock, regardless of when in the session it occurred. Control sessions in which only two shocks were programmed, one early and one late, did not yield baseline acceleration. Evidence of "counting to three" was less obvious in subjects simultaneously exposed to a temporal autocontingency, that is, for which each shock also predicted a minimum 3-min safety period. The addition of a sigmal prior to each shock eliminated evidence of counting behavior altogether. We conclude that rats may be taught to count, but such behavior is highly unnatural and may be blocked or overshadowed by more salient sources of information.
\end{abstract}

Although Clever Hans, the counting horse, appears to be a permanent part of our psychological folklore (Watson, 1914), the formal possibility that infrahuman animals can count has received little serious attention in the modern experimental literature.

In this paper, we will present evidence that rats can count to three to predict safety from shock. In evaluating our results, we have considered definitions of counting adapted from human performance. However, even the mechanisms that underlie counting behavior in humans are far from understood (cf. Gelman \& Gallistel, 1978; Piaget, 1952). We have therefore adopted the view of counting that is typically held in infrahuman research, viz, an animal is assumed to be counting if behavioral sensitivity to number-related stimuli can be demonstrated. This view requires that all alternative, and presumably simpler, sources of control, such as changes in exteroceptive stimuli or temporal cues, be precluded.

We have recently reviewed a variety of evidence that suggests that infrahuman animals are, in fact, capable of counting (Davis \& Memmott, 1982). For example, Davis and McIntire (1969) reported that when three unsignaled shocks were regularly superimposed upon a baseline of food-reinforced leverpressing, responding did not remain totally suppressed, but, rather, recovered immediately following delivery of the third shock. Seligman and Meyer confirmed these findings and concluded that "rats act as if they are able to 'count to three' and use

The preparation of this paper was supported in part by Orant A06973 from the Natural Science and Engineering Research Council of Canada to Hank Davis, and by an NSERC postdoctoral fellowship award to John Memmott. Reprints may be obtained from Hank Davis, Department of Psychology, University of Guelph, Guelph, Ontario N1G 2W1, Canada. the information conveyed by the third shock-no further shock-as a safety signal" $(1970$, p. 206).

In order to explore this source of control, Davis, Memmott, and Hurwitz (1975) introduced the concept of autocontingencies (ACs), subtle relationships among stimulus events that often go undetected by the experimenter. Our initial work described two types of subtle shock-shock relations. The first, known as a temporal AC, involved a regularly programmed shock-free period immediately following each shock. Under this temporal AC, shock itself becomes a signal for a brief shock-free period. We have since confirmed that when no other predictive information is available, temporal ACs result in dramatic acceleration of operant responding (thus indicating safety) for a brief period following each shock (Davis, Herrmann, MacFadden, \& Ellen, 1977; Davis, Herrmann, \& Shattuck, 1979; Davis \& MacFadden, 1978; Davis et al., 1975).

The second kind of shock-shock relation we described is termed a ratio AC. This procedure is directly relevant to counting behavior. Our initial research strongly suggested that when three shocks regularly occurred in each session, offset of the third shock became an effective predictor of safety. In the absence of other predictors, the animal's behavior typically remained suppressed until the final shock occurred, at which point responding was accelerated for the balance of the session. Moreover, occasional probe trials in which all three shocks occurred relatively early within the session revealed that conditioned acceleration was not dependent upon temporal cues; that is, animals began to respond following the third shock, whether it occurred early or late in the session.

Despite the compelling nature of these findings, we now have reason to question the method by which the results of our ratio ACs were analyzed. The tech- 
nique was borrowed directly from Seligman and Meyer (1970), who compared the percentage of session time following the third shock with the percentage of total responding that occurred during this period. Because all of the obtained disparities were positive, the evidence seemed to suggest that responding was accelerated by offset of the third shock.

The problem with this analysis lies in its underlying assumption that response rate, unless it is disrupted by some salient event, will remain constant throughout the session. Along with other investigators (e.g., Ayers, Berger-Gross, Kohler, Mahoney, \& Stone, 1979), we have come to question this premise. Recent findings in our laboratory (Davis, Shattuck, \& Wright, 1981) make it clear that systematic changes occur in the rate of baseline operant responding during exposure to shock-based AC procedures. Specifically, we have reported that responding is most suppressed early in the session and recovers gradually as the session progresses. This has obvious implications for the analysis of counting under ratio ACs. If baselines are, in fact, increasing within the session, then it is naive to compare percentages of responses with percentages of session time. The use of such an analysis by Seligman and Meyer (1970), as well as in our earlier work (Davis et al., 1975), resulted in strong evidence of post-third-shock acceleration, but makes it difficult to isolate the accelerative contribution of the third shock from that of an already increasing baseline.

The following experiment was run to elaborate our previous suggestive findings and provide solid empirical support for counting behavior in rats. To this end, we will take a more conservative look at postthird-shock acceleration of baselines that are already presumed to be increasing. In addition, we will use systematic probe procedures to examine the roles played by "counting" as opposed to temporal cues in producing post-third-shock acceleration.

\section{METHOD}

\section{Subjects}

The subjects were 16 experimentally naive male hooded rats of the Long-Evans strain. They were approximately 120 days old at the start of the experiment and weighed between 390 and $479 \mathrm{~g}$. Subjects were maintained at $80 \%$ of their free-feeding weights throughout the experiment.

\footnotetext{
Apparatus

Three rodent test chambers (Campden Instrument Co.) were used. The chambers, housed in sound-attenuation shells, were equipped with retractable levers which required a minimum downward force of $15 \mathrm{~g}(.14 \mathrm{~N})$ for activation. Only the left lever was functional during the experiment. The grid floor comprised 16 stainless steel rods through which scrambled shock could be delivered. Delivery of 1-sec .6-mA shock to the grids, walls, and lever of each chamber served as the unconditioned stimulus (US). The conditioned stimulus (CS) was a 1 -min tone $(90 \mathrm{~dB}$, re .0002 dynes/ $\mathrm{cm}^{2}$ ) produced by a Mallory Sonalert (Model SC $628 \mathrm{H}$ ), mounted directly over each test cage. The reinforcer was $.045-\mathrm{g}$ Noyes food
}

Table 1

Summary of Experimental Treatments

Preliminary VI training

20 sessions

Phase 1: Autocontingency experience

Groups $A C$ and no-AC:

3 shocks $/ 30$-min session

Group AC:

Minimum 3-min intershock interval

Group no-AC:

No minimum 3-min intershock interval

Phase 2: Probe sessions

A-Early probe:

Third shock delivered by Minute 12

B-Two-shock probe:

Only two shocks delivered, one early and one

late in session

Phase 3: Signaled shock training

Introduction of CS prior to each shock and

conditions maintained as in Phase 1

pellets delivered into a food magazine in the lower center of the front wall of the chamber.

\section{Procedure}

The sequence of experimental treatments is summarized in Table 1. After preliminary leverpress training, all rats were exposed to a variable-interval (VI) 30-sec schedule (range: $4-90 \mathrm{sec}$ ) for 2030 -min sessions. Visual inspection of cumulative response records at the end of VI training revealed stable rates of response.

Phase 1. Autocontingency (AC) experience began on the 21 st session with the introduction of shock. The number of shocks delivered during each 30-min session was fixed at three. Thus, for all animals, delivery of the third shock signaled safety from shock for the remainder of the session. Half the rats $(\mathbf{N}=\mathbf{8})$ were assigned randomly to condition $A C$, in which a temporal $A C$ was programmed such that shocks were always separated by an interval of at least $3 \mathrm{~min}$. Therefore, in addition to the period of safety signaled by the third shock, brief periods free from shock were also signaled by offset of Shocks 1 and 2. The remaining animals $(\mathrm{N}=8)$ were assigned to condition no- $\mathrm{AC}$ in which this temporal constraint on the delivery of shock was removed. For these rats, only the period following offset of the third shock signaled safety. These procedures were maintained for 90 sessions.

Phase 2. Beginning with Session 111, probe sessions were interspersed among regular training trials over the following 24 sessions. Probe sessions were included in order to assess the role of temporal factors in maintaining post-third-shock acceleration. Two types of probe conditions were run. In early-probe sessions, all three shocks were delivered early in the session: in all cases, delivery of the third shock occurred no later than Minute 12 of the session. In two-shock probe sessions, only two shocks were presented: one early in the session (Minute 4) and the other late in the session (Minute 27). During Phase 2, a probe session was administered after every third regular training session, and three sessions of each type of probe were included in a randomly programmed sequence.

Phase 3. At the conclusion of probe testing, AC experience was reinstated. In addition, however, a 60 -sec presentation of tone now preceded and terminated with the delivery of each shock. Signaled shock conditions were maintained for 25 sessions.

\section{RESULTS}

Our previous analysis of accelerative control by the third shock was based on the assumption that re- 
sponse rate remained unchanged throughout the session. Disparities from such estimates of performance were interpreted as evidence of conditioned acceleration. The present experiment employed a more conservative estimate of baseline responding which took into account the fact that baselines typically increase during the session. A "predictor equation" was derived from each subject's performance, based upon the cumulative percentage of responses determined at successive 5 -min intervals for the first $20 \mathrm{~min}$ of each session. This equation established the representative pattern of responding for the session, taking into account within-session increases that were occurring. It was thus possible to predict the percentage of total responses that should occur following the third shock, based solely on known increases in the rate of responding and excluding any rapid acceleration produced by offset of the third shock. ${ }^{1}$

Following establishment of a predictor equation for each session, the number of responses emitted between offset of the third shock and the end of the session was calculated for each rat. That number was then expressed as a percentage of the total number of responses made during the session. The disparity between the percentage values actually obtained and those derived from the predictor equation provided an index of the degree of post-third-shock control.

\section{Phase 1}

Temporal AC control. The eight animals exposed to a minimum of 3-min intershock interval all showed the accelerative effects of this temporal $A C$. An $\mathbf{A} /(\mathbf{A}+\mathbf{B})$ ratio $(A=$ mean responding in the minute following shock; $B=$ mean responding in all remaining minutes of the session) was employed to assess the degree of accelerative control during postshock minutes. Ratio values in excess of .50 indicate accelerated responding relative to baseline. The mean ratio value obtained for all subjects during the final five sessions of Phase 1 was .64, indicating substantial acceleration of baseline rates following each shock offset. Comparable ratios for Group no-AC averaged .48 , indicating a lack of accelerative control in the absence of the shock/no-shock AC.

Post-third-shock control. Phase 1 data are summarized in Table 2. A comparison of obtained and expected values indicates that responding was strongly accelerated following offset of the third shock. For both AC and no-AC groups, the percentage of obtained responding exceeds the percentage derived from predictor equations. The disparity between expected and observed values was greater in Group no-AC, thereby suggesting that post-third-shock control was stronger in the absence of a temporal AC.

Although the difference between expected and observed percentages was significant under both con-
Table 2

Observed and Expected Percentages of Responding Following Third Shock During Final Five Sessions of Each Phase of Experiment

\begin{tabular}{ccc}
\hline Observed Expected & \\
Percentage Percentage & Significance \\
\hline
\end{tabular}

\begin{tabular}{|c|c|c|c|}
\hline \multicolumn{4}{|c|}{ Phase 1} \\
\hline $\begin{array}{l}\text { All subjects } \\
\text { AC subjects } \\
\text { no-AC subjects } \\
\text { AC vs. no-AC }\end{array}$ & $\begin{array}{l}67.04 \\
57.06 \\
77.02\end{array}$ & $\begin{array}{l}40.40 \\
36.39 \\
44.42\end{array}$ & $\begin{array}{l}t(15)=9.13, p<.001 \\
t(7)=7.17, p<.001 \\
t(7)=7.68, p<.001 \\
t(14)=2.32, p<.05\end{array}$ \\
\hline \multicolumn{4}{|c|}{ Phase 2: Early Probe } \\
\hline $\begin{array}{l}\text { All subjects } \\
\text { AC subjects } \\
\text { no-AC subjects } \\
\text { AC vs. no-AC }\end{array}$ & $\begin{array}{l}87.27 \\
81.48 \\
93.06\end{array}$ & $\begin{array}{l}71.56 \\
69.77 \\
73.35\end{array}$ & $\begin{array}{l}t(15)=8.09, p<.001 \\
t(7)=3.94, p<.01 \\
t(7)=9.29, p<.001 \\
t(14)=2.35, p<.05\end{array}$ \\
\hline \multicolumn{4}{|c|}{ Phase 2: Two-Shock Probe } \\
\hline $\begin{array}{l}\text { All subjects } \\
\text { AC subjects } \\
\text { no-AC subjects } \\
\text { AC vs. no-AC }\end{array}$ & $\begin{array}{l}36.02 \\
32.05 \\
39.99\end{array}$ & $\begin{array}{l}42.73 \\
42.29 \\
43.17\end{array}$ & $\begin{array}{l}t(15)=1.59, p>.05 \\
t(7)=1.59, p>.05 \\
t(7)=0.61, p>.05 \\
t(14)=0.83, p>.05\end{array}$ \\
\hline \multicolumn{4}{|c|}{ Phase 3} \\
\hline $\begin{array}{l}\text { All subjects } \\
\text { AC subjects } \\
\text { no-AC subjects } \\
\text { AC vs. no-AC }\end{array}$ & $\begin{array}{l}38.75 \\
37.85 \\
39.60\end{array}$ & $\begin{array}{l}34.10 \\
36.06 \\
32.15\end{array}$ & $\begin{array}{l}t(15)=1.36, p>.05 \\
t(7)=0.86, p>.05 \\
t(7)=1.08, p>.05 \\
t(14)=-0.83, p>.05\end{array}$ \\
\hline
\end{tabular}

Note-Disparity between expected and observed values provides evidence of counting, that is, post-third-shock acceleration. $A C=$ autocontingency.

ditions, these values would have been even larger had we adopted the prediction technique employed by Davis et al. (1975) and Seligman and Meyer (1970). This less conservative estimate of baseline performance would have yielded expected values of $32.2 \%$, $29.4 \%$, and $35.1 \%$ for all subjects, Group $A C$, and Group no-AC, respectively.

\section{Phase 2}

Probe sessions were interspersed among regular training sessions in order to evaluate the role played by temporal as opposed to "counting" factors in maintaining post-third-shock acceleration. The probe data reported in Table 2 are based upon the same predictor equations employed for Phase 1.

Early probe. Under the early-probe condition, all three shocks were delivered by Minute 12 of the session. Early-probe sessions were designed to test whether post-third-shock acceleration would occur despite the presence of early-session temporal cues, normally associated with suppressed baselines. Table 2 indicates that for both $A C$ and no-AC groups, the third shock was strongly accelerative, despite its occurrence during the normally suppressed early portion of the session. Although all subjects showed strongly accelerated responding relative to predicted estimates, control by the third shock was 
stronger in Group no-AC, which had no simultaneous predictors of "safety."

Two-shock probe. Only two shocks were presented under the two-shock probe condition, one early in the session and the other late. Two-shock probe sessions tested the specificity of response acceleration to the third shock. These trials determined whether accelerative effects could be similarly obtained following offset of Shock 2, if that event occurred late in the session, when responding was normally accelerated. Table 2 shows that there was no disparity between expected and observed response percentages, thereby indicating that conditioned acceleration depends upon the occurrence of the third shock, rather than the occurrence of any shock late in the session.

\section{Phose 3}

The effects of introducing a CS prior to each shock are reported in Table 2 and summarized below.

Baseline responding. Rates of responding during non-CS minutes of the session substantially increased from Phase 1 under the signaled-shock condition (Group AC, 6.3 vs. 11.8; Group no-AC, 7.4 vs. 12.1). An analysis of combined group data revealed the Phase 3 increases to be significant $[t(15)=4.17$, $p<.001$ ]. The degree of baseline recovery produced by the CS did not differ between groups $[t(14)=.36$, p > .05].

Conditloned suppression. A conventional suppression ratio $A /(A+B)$ revealed that rates of responding during the $1-$ min CS prior to shock were significantly reduced for all subjects. The mean suppression ratio recorded for the final five sessions in Phase 3 was .024. Suppression ratios did not differ between groups $[\overline{\mathrm{X}}=.03$ vs. .02 for Group AC vs. Group no-AC; $t(14)=1.33, p>.05]$.

Temporal AC control. The mean ratio value for AC subjects was reduced to .49 during the final five session of Phase 3, indicating that the presence of a CS prior to shock eliminated previously established control under the temporal AC.

Post-third-shock control. Because baselines were significantly increased by the addition of a CS, new predictor equations were calculated for each subject in Phase 3. These equations were established according to the procedures described earlier and were based on the first 20 minutes of responding averaged over the final five sessions of signaled shock training.

The effects of the CS on accelerative control exerted by the third shock are summarized in Table 2. For both groups of subjects, response acceleration was eliminated following the third shock; that is, there was no disparity between expected and observed patterns of responding. There are two ways in which post-third-shock acceleration might appear to decline: either by an increase in the expected response percentage or by a decrease in the obtained percentage. An examination of Phase 1 data revealed that loss of control in Phase 3 was primarily based upon obtained reductions in acceleration following the third shock.

\section{DISCUSSION}

As in our previous work with ACs, we have used conditioned acceleration of operant responding in order to infer the occurrence of discriminative control based upon the number of shocks (e.g., Davis et al., 1975). There is strong evidence from the present experiment that all rats tested were able to count to three, and to use this information to predict periods free from shock.

In Phase 1, rate of responding was strongly enhanced following offset of the third shock. This effect was significant even when measured against a baseline estimate that took into account the progressive increase in response rate produced by these conditions. In Phase 2, the results of probe sessions indicate that conditioned acceleration reflects ratio, rather than temporal, control, that is, that animals were counting the number of shocks rather than using the passage of time to detect safety. This is clear both from the conditioned acceleration that occurred when the third shock was delivered early in the session and from the absence of conditioned acceleration following delivery of the second shock late in the session.

The addition of a CS prior to each shock delivery in Phase 3 eliminated not only evidence of thirdshock control, but also of control under the temporal AC. This result is consistent with our previous findings and underscores the importance of what we have described as "need" in our earlier analysis of AC control (Davis et al., 1975). That is, although control by subtle stimulus relations based on time or counting may be both potent and reliable, its occurrence is generally restricted to those instances in which other, more salient predictors are absent. To the extent that alternative predictors of safety were available under a tone-shock contingency in Phase 3, or a temporal autocontingency in Phase 1 , the "need" to count shocks diminished and the evidence for counting behavior was weaker.

This conclusion parallels a strong suggestion, gleaned from our survey of the literature, that counting behavior in animals is most likely to emerge under relatively extreme experimental conditions, for example, following extensive testing or when safety is at a premium (Davis \& Memmott, 1982; Ferster, 1958, 1964; Razran, 1965). It underscores the view that, for infrahuman animals, counting represents an unnatural behavior, one that may have virtually no evolutionary significance. In short, we have ex- 
amined a behavior that represents at best an unprepared, and perhaps a relatively contraprepared associative process (Seligman, 1970). By definition, counting may tell us little about the animal's natural existence. However, the analysis of counting behavior in rats and other infrahuman species may begin to shed light on those abilities that lie on the boundary of an organism's perceptual and associative capacities.

Although we have not identified the underlying mechanism, we have provided evidence that rats can count to three. It is quite likely, however, that the rat's ability to count is limited by both time and number. Thus, our success may be tied to having chosen both an optimal number of events (three), as well as a suitable temporal framework ( $30 \mathrm{~min})$. In this regard, a recent attempt to replicate our findings by Imada (1981, Note 1) has seemingly produced negative results. Imada and his colleagues (e.g., Imada \& Okamura, 1975; Imada, Sugioka, Ohki, Ninohira, \& Yamazaki, 1978) have reported a series of experiments on the rat's ability to use relatively subtle cues as predictors of danger and safety. In the most recent experiment, Imada exposed rats to a conditioned suppression procedure involving either signaled or unsignaled shock and a fixed or variable number of shock deliveries per session. Under the critical fixed-unsignaled case, three shock deliveries per session led to post-third-shock acceleration in only one of seven rats. The remaining animals either showed sustained post-first- or post-second-shock acceleration (two subjects) or remained generally suppressed throughout the session (four subjects).

There are at least two factors that could account for Imada's failure to replicate our evidence of counting. Imada used a licking baseline as opposed to the present leverpressing response, but perhaps the more telling procedural difference concerns session length. Three shocks in the present procedure were delivered during a 30-min session, whereas Imada's procedure lasted only $5 \mathrm{~min}$. Recent research in our laboratory (Davis et al., 1981) has indicated that there are optimal trial densities for demonstrating control by temporal ACs. It is quite likely that the same is true for demonstrating ratio AC control (i.e., post-third-shock acceleration). Thus, it is our belief that the optimal conditions for counting were exceeded by the extremely brief session length and resultant high shock density employed by Imada.

It remains to be demonstrated whether rats can count three shocks when they occur over a 60 - or 120 min session. A recent attempt to train rats to count six shocks in a 45-min session did not meet with success, although some suggestive evidence was recorded (Davis et al., 1981). In short, the present results establish a procedure under which rats can be taught to count, but do not suggest the limits of this ability.
On the basis of our literature review (Davis \& Memmott, 1982), as well as our own research, we conclude that counting behavior appears to lie within the abilities of most infrahuman animals. However, we do not believe that counting, once learned, will, unlike reading, pressing a lever, or riding a bicycle, appear whenever possible. Rather, we suggest that counting may be conceived as a "last resort" in terms of an infrahuman's perceptual-cognitive "strategies." Its occurrence requires considerable environmental support, and there is little reason to expect transsituational generality, unless subsequent test situations are equally extreme or impoverished in alternative sources of information. In short, animals will not continue to count simply because they have been taught to; counting will occur only when it is demanded by the environment.

\section{REFERENCE NOTE}

1. Imada, H. Personal communication, April 11, 1981.

\section{REFERENCES}

AyAgh, J. J. B., Berger-Gross, P., Kohler, E. A., Mahoney, W. J., \& STONE, S. Some orderly nonmonotonicities in the trialby-trial acquisition of conditioned suppression: Inhibition with reinforcement? Animal Learning \& Behavior, 1979, 7, 174-180.

Davis, H., Herrmann, T., MacFadden, L., \& Ellen, P. Do septal lesions eliminate behavioral control by an autocontingency? Physiological Psychology, 1977, 5, 339-342.

Davis, H., Herrmann, T., \& ShatTuck, D. Summation of excitatory and inhibitory control produced by traditional toneshock contingencies and autocontingencies. Pavlovian Journal of Biological Science, 1979, 14, 254-262.

DAvis, H., \& MAcFAdDeN, L. Is autocontingency control established when a traditional contingency is simultaneously available? Bulletin of the Psychonomic Society, 1978, 11, 387-389.

Davis, H., \& McIntire, R. W. Conditioned suppression under positive, negative, or no contingency between conditioned and unconditioned stimuli. Journal of the Experimental Analysis of Behavior, 1969, 12, 633-640.

Davis, H., \& MEMmotr, J. Counting behavior in animals: A critical evaluation. Psychological Bulletin, 1982, 92, 547-571.

Davis, H., Memmotr, J., \& Hurwitz, H. M. B. Autocontingencies: A model for subtle behavioral control. Journal of Experimental Psychology: General, 1975, 104, 169-188.

Davis, H., ShatTucr, D., \& Wright, J. Autocontingencies: Factors underlying control of operant baselines by compound tone/shock/no-shock contingencies. Animal Learning \& Behavior, 1981, 9, 322-331.

Ferster, C. B. Intermittent reinforcement of a complex response in a chimpanzee. Journal of the Experimental Analysis of Behavior, 1958, 1, 163-165.

Ferster, C. B. Arithmetic behavior in chimpanzees. Scientific American, 1964, 210, 98-106.

Gelman, R., \& Gallistel, C. R. The child's understanding of number. Cambridge, Mass: Harvard University Press, 1978.

Imada, H., \& Okamura, M. Some cues rats can use as predictors of danger and safety. Animal Learning \& Behavior, $1975,3,221-225$.

Imada, H., Sugloxa, K., OHRi, Y., Ninohira, H., \& Yamazaki, A. The effects of double-alternation schedules of shock intensity upon patterning of suppression of licking in rats with special 
reference to cue-utilization. Japanese Psychological Research, $1978,20,167-176$.

Piaget, J. The child's conception of number. London: Rutledge Kegan, 1952.

RAzran, G. Empirical codifications and specific theoretical implications of compound-stimulus conditioning: Perception. In W. F. Prokasy (Ed.), Classical conditioning. New York: Appleton-Century-Crofts, 1965.

Selioman, M. E. P. On the generality of the laws of learning. Psychological Review, 1970, 77, 406-418.

Seliaman, M. E. P., \& Meyer, B. Chronic fear and ulceration in rats as a function of unpredictability of safety. Journal of Comparative and Physiological Psychology, 1970, 73, $202-207$.

Watson, J. B. Behavior: An introduction to comparative psychology. New York: Holt, Rinehart \& Winston, 1914.

\section{NOTE}

1. The use of a 20 -min period to estimate baseline responding was justified in terms of the convenience of data collection, as well as its being logically sound. On the average, the third shock occurred during Minute $\mathbf{2 2 . 1 7}$ of the session, and in $75 \%$ of the cases delivery of the third shock occurred during or after Minute 20.

Because it has been determined that increases in the rate of baseline responding are predominantly linear (Davis et al., 1981), the exclusion of bascline data beyond Minute 20 does not substantially affect the predictor equation. On the other hand, the inclusion of postshock data in those cases in which the third shock occurred prior to Minute $\mathbf{2 0}$ actually results in a more conservative lest of conditioned acceleration. Such postshock data inflate estimates of expected baseline rate, and make it more difficult to detect differences between expected and observed response totals, which are used to determine the degree of acceleration.

(Munuscript received November 24, 1981; revision accepted for publication August 6, 1982.) 